\title{
Possibilities of 3D scanning of parts during repair of agricultural machinery
}

\author{
Ivan Golubev
}

Russian Research Institute for Information and Technical and Economic Research on the Engineering and Technical Support of the Agro-Industrial Complex, 60, Lesnaya St., Pravdinsky Moscow Region, 141260, Russian Federation

\begin{abstract}
New high-precision and productive tools are needed due to the increasing requirements to the finishing accuracy of reworked parts and the assembly of units and machines in repair production. One of the most dynamically developing areas of digital production is the use of 3D technologies. They are most actively used in the aviation and automotive industry, as well as in the manufacture of machine elements from various parts. In recent years, there have been some publications on the use of 3D technologies in the repair of machines, including the reconditioning and hardening of parts. The current global trend is the creation of digital measurements and systems for contactless optical quality control of products. The paper and analyzes 3D scanning technologies developed by scientific and educational organizations, as well as presented at various international specialized exhibitions. The analysis and synthesis of information revealed that various laser scanners have been developed and used for 3D scanning, mainly for manufacturing quality control. The study analyzes the possibilities of their use to monitor the geometric parameters of parts of agric
\end{abstract}

ultural machines during the input control of spare parts and repair of machines. 3D scanning has been found to improve measurement accuracy and performance compared to contact tools. The paper presents the main directions of 3D technologies in repair production. A promising area of introducing 3D technologies into repair production is the integrated use of additive technologies and 3D scanning. In case of fault detection using a 3D scanner, the wear value is determined, and the 3D printer recovers the wornout surface taking into account the non-uniformity of wear. Thus, the additive material consumption is reduced from 20 to $90 \%$.

\section{Introduction}

Quite often the operability of machines and equipment in the agro-industrial complex has to be supported by maintenance and repair measures. They require a large number of measurements, including incoming inspection of spare parts, defect and quality control of reworked parts and other operations [1]. New highprecision and productive tools are needed due to the increasing requirements to the finishing accuracy of reworked parts and the assembly of units and machines in repair production [2]. The Strategy for Scientific and Technological Development of the Russian Federation [3] states that the priorities and prospects for the scientific and technological development of the Russian Federation in the next 10-15 years include the transition to advanced digital, intelligent production technologies, robotic systems, new materials and design methods, the creation of systems for processing large amounts of data, machine learning and artificial intelligence [4]. One of the most dynamic areas of digital production is the use of $3 \mathrm{D}$ technologies. They are most actively used in the aviation and automotive industry, as well as in the manufacture of machine elements from various parts [5]. In recent years, there have been some publications on the use of 3D technologies in the repair of machines, including the reconditioning and hardening of parts. The current global trend is the creation of digital measurements and systems for contactless optical quality control of products [6].

\section{Problem Statement}

The repair of agricultural machinery implies a variety of measurements, including during the input control of spare parts, defects and quality control of reworked parts and other operations. The reliability and accuracy of such measurements depend on the quality of the technological processes and the costs of repairing the equipment. Depending on the complexity of the equipment, the share of such costs in the total volume is $10-50 \%$ [2]. Therefore, it is necessary to increase the efficiency of metrological support for repair production, including the use of 3D scanning

\footnotetext{
*Corresponding author: i.g.golubev@mail.ru
} 
technologies. In recent years, there have been some publications on the use of 3D technologies, including 3D scanning during machine maintenance. 3D scanning (3D digitization) is a method of obtaining data on the shape and size of an object in a spatial representation by writing $\mathrm{x}, \mathrm{y}$ and $\mathrm{z}$ coordinates of points of an object surface and converting a set of points into an electronic geometric model using specialized software. Various scanners have been developed and used for 3D scanning. They may be used to control geometric and physical-mechanical parameters of parts of agricultural machines during the input control of spare parts and machine maintenance [7]. 3D scanning improves the measurement accuracy and performance compared to contact tools. A modern trend in mechanical engineering is the use of $3 \mathrm{D}$ scanning in convergent modeling technologies and in additive production.

\section{Research Methods}

The analysis was based on the articles in periodicals and on websites, factographic and documentary databases of Rosinformagrotekh, as well as other open information sources of various organizations on 3D scanning technologies, including the Central Scientific Research Automobile and Automotive Engine Institute "NAMI", Russian State Agrarian University - Moscow Timiryazev Agricultural Academy, Federal Scientific Agroengineering Center VIM, Moscow Polytechnic University, and others. Great attention is paid to the study and analysis of 3D scanning technologies and equipment presented at various annual exhibitions, including the international specialized exhibition "Machine Tools", "Additive Technologies and 3D Printing in Industry", "Equipment and Technologies for Processing Structural Materials", "Technoforum of the exhibition of additive technologies in industry", 3D fab + print Russia, which takes place within the framework of the International specialized exhibition of plastics "Interplastica", etc. The research process used such methods as information analysis and synthesis, expertise, information and analytical monitoring.

\section{Findings}

The analysis showed that 3D scanning technologies are promising for mechanical material maintenance. To do this, various scanners have been developed and used. They are used mainly for quality control of manufactured parts. However, they are promising for assessing geometric and physical-mechanical parameters, surface quality of agricultural machinery during input, output and current quality control of production, defect and reconditioning of parts during machine maintenance. 3D scanners are devices for three-dimensional measurements that are used to obtain data on real objects for their subsequent processing and analysis using digital technologies. 3D scanners do not need to contact a scanned object, they may be used to fully or partially 3D measure any material object. Most of these devices generate extremely high density points compared to traditional contact measurement devices, which gives much more information about the object being measured [7]. Software for 3D scanners has been developed by various developers. For example, Geomagic Control X Inspection Software may be used for surface inspection and linear sizing of various parts. It is possible to set a size and tolerance for each plane. Therefore, in mass production, quality control will take much less time: it is enough to configure the measurement algorithm once. For assembly plants, Geomagic Control X may be used to identify defects in parts received from suppliers [7].

One of Creaform's well-known metrological equipment models is Metra SCAN and Handy PROBE. Metra SCAN is a laser 3D scanner designed for highspeed scanning and precision measurements of large complex objects. Handy PROBE is a portable coordinate-measuring machine that replaces traditional measuring hands, it allows measuring simple objects (planes, cones, cylinders, etc.) and saving the measurement results in the form of CAD data.

The principle of the laser scanner is based on the triangulation method of measuring the distance to the object. This method is based on the following: a laser beam emanating from the source, which differs from ordinary light by high parallelism of the beam, falls on the surface. Further, part of the incident beam is reflected from this surface and enters the receiver. On the receiver, the lens focuses the reflected beam on the CCD array, where the position of the bright spot on the array indicates the direction of the incoming beam, i.e. the angle between the laser beam and the returned light. The reflection angle of the laser varies depending on the distance to the object and thus the position of the laser point on the receiver is changed. Given that the laser beam source and the receiver are fixed and spaced apart, the reflection angle may be measured by simple geometric construction. As a result, three parameters are determined: the distance from the receiver to the source, the angle between the beam emitted by the laser and the receiver-laser line and the angle between the reflected beam and the receiver-laser line. According to these parameters, it is possible to restore all the sides and angles of the triangle, including the distance to the object [7].

Creaform's equipment allows enterprises solving various technical problems: measurement of linear and angular dimensions, analysis of shape deviations, analysis of deformation and wear of parts. Laser scanning is actively used in flaw detection, since it allows obtaining data on the presence and structure of even the smallest pores, which is important when determining defects in parts such as the head of the engine cylinder block. 
The analysis of foreign and domestic sources showed that 3D scanning is used to control the accuracy of parts after hot bulk stamping, measuring forging, tool wear and other processes in mechanical engineering [8-11]. So suring laser scanning the time spent checking geometry was reduced from 20 minutes to a minute. Besides, the number of rejected parts in the batch decreased by 95\% [12]. Compared to the conventional technique of measuring forging using manual measuring tools, a time reduction of $33 \%$ was achieved [13]. ATOS III Triple Scan scanner that is used to scan sheet metal parts reduces the measurement time for their dimensions by 50-85\% [14]. EINSCANPRO 2XPLUS 3D scanners are also applied in practice (Table 1).

Table 1. Specifications of EINSCANPRO 2XPLUS 3D scanner

\begin{tabular}{|l|l|l|}
\hline Indicator & $\begin{array}{l}\text { Manual } \\
\text { scanning }\end{array}$ & $\begin{array}{l}\text { Fast-speed } \\
\text { manual } \\
\text { scanning }\end{array}$ \\
\hline Scanning accuracy, mm & Up to 0.05 & Up to 0.1 \\
\hline Scanning rate, shot/s & 20 & 30 \\
\hline $\begin{array}{l}\text { Distance between } \\
\text { points, mm }\end{array}$ & $0.2-2$ & $0.2-2$ \\
\hline Texture scanning & No & Yes \\
\hline
\end{tabular}

KREON Technologies laser scanners are also used to control the geometry of parts. They give an error of $\pm 15 \mu \mathrm{m}$ and higher. The principle of operation of the laser scanner is as follows: it is attached and connected to a test machine (TM). In compliance with preset program, the TM carriage moves the scanner along the part. The laser beam, reflecting from the measured surface, is fixed by an optical camera and digitized using software into a cloud of points, on which a 3D surface is subsequently built [5]. Tomelleri Engineering instrument arms are used for quality control, measurement, reverse engineering and 3D modeling. Laser scanners make instrument arms a means for quick and accurate 3D control, digitization and analysis of the obtained data. Such means may be used in various industries, including repair production. Tomelleri Engineering instrument arms are compatible with NIKON METROLOGY laser scanners.

The specifications of NIKON METROLOGY laser scanners are given in Table 1.

Table 2. Specifications of NIKONMETROLOGY laser scanners

\begin{tabular}{|l|l|l|}
\hline $\mathrm{n} / \mathrm{n}$ & Indicator & MMDx50 \\
\hline 1 & Scanning accuracy, $\mu \mathrm{m}$ & 14 \\
\hline 2 & Line width, mm er for & 50 \\
\hline 3 & $\begin{array}{l}\text { Scanning error } \\
\text { SPACEPlus } 1.8, \mu \mathrm{m}\end{array}$ & \\
\hline
\end{tabular}

In Russia, there are various scanning measuring devices to repair machines. The Russian State Agrarian University - Moscow Timiryazev Agricultural Academy developed an automated measuring device for monitoring geometric and physical-mechanical parameters, surface quality of agricultural machinery parts. The device increases accuracy and efficiency of measurements compared to contact devices. The device design uses a $2 \mathrm{D}$ laser scanner. The principle of operation of the automated measuring device is based on the $2 \mathrm{D}$ determination of the coordinates of the points of the light line projected onto the surface of the controlled spare part, as well as the mass and other physical and mechanical properties of the material of the controlled spare part, transmission of data to the control system of their processing, which automatically analyzes the results of monitoring, concludes that the spare part is serviceable, controlled in accordance with the program of data on possible defects included in it, type and parameter of the controlled spare part [5]. At the Central Scientific Research Automobile and Automotive Engine Institute "NAMI" 3D scanning of surfaces is first carried out to control deviations in the geometric parameters of parts. The scan data is then mapped to the original CAD model from which the part was manufactured. Deviations over the entire surface are displayed as a color map. The surface geometry mapping report is saved in a PDF file. The DEA Global Performance coordinate-measuring machine may be used for scanning. The machine is used to control the dimensions of crankshafts and camshafts, cylinder block heads, cylinder blocks, body parts, etc. It is especially effective in high-precision control of the geometry of parts after machining. It is equipped with ruby probes and a rotary head, which provides control using five axes. In Bashkir SAU, the defect of the worn-out crankshaft of the ZMZ-409 engine was carried out using a portable 3D scanner Artec Eva Lite. To do this, the software product Geomagic Control X was used, which provides for a $3 \mathrm{D}$ analysis of the part and high-precision measurements, determines wear of mutually rubbing surfaces, the presence of microcracks, damage to internal holes and cavities of complex-shape parts. To rework the crankshaft, a technology route diagram was drawn up. The results of measurements obtained using metrological instruments and reports were compared in Geomagic Control X. This method allows increasing the defect efficiency, reducing its duration by 6 times, reducing the level of subjectivity of assessing the technical state of the part and reducing the labor input by $30 \%$ [15]. At the moment, a digital 3D farm is operating on the basis of the Federal Scientific Agroengineering Center VIM, which allows for the minimum design and manufacture of parts and assemblies of agricultural machinery. During the operation of the site, the geometry of the worn part is checked by superimposing a digital model after its 3D scanning with a drawing of the factory part. This technology allows you to determine the amount of wear and justify recommendations on the suitability of the worn part for further use, including for replacement or restoration, based on the obtained deviations of the measured values of the geometric parameters of the digital and factory drawing of the part. At the repair site, the parts are made mainly by FDM and SLA methods. With a scientifically-based selection of 
consumables (powders, foils, etc. ) for 3D printing, it is possible to produce parts with the same physical and mechanical properties (hardness, wear resistance) as with the original spare parts [7]. The introduction of 3D scanning sites for worn parts is advisable at service enterprises for the repair of expensive foreign agricultural machinery, which is used in large volumes in the agro-industrial complex of the Russian Federation. The need to organize the restoration of worn parts of such equipment is caused primarily by the high cost of original spare parts. However, during the technological preparation of production facilities and the development of technology for restoring parts of foreign equipment, difficulties arise due to the lack of regulatory and technical documentation, including design and technological, as well as repair drawings, at repair enterprises. Therefore, the organization of the 3D scanning site at the repair plant will allow you to quickly reverse-engineer worn parts of agricultural machinery and obtain their digital CAD models and drawings.

One of the promising directions of introducing 3D technologies into repair production is the integrated use of additive technologies and 3D scanning. When the parts are defective after the disassembling of repaired machine units a 3D scanner is used to determine the wear value, and a 3D printer reworks the worn-out surface taking into account wear unevenness. The advantages of this repair technology include improved measurement accuracy, reduced range of measurement tools, the possibility of restoring parts of complex geometric shape; the additive material layer is applied directly at wear point. Thus, the material consumption is reduced from 20 to $90 \%$. Additive technologies allow applying special coatings to parts such as cylinder liners, piston rings, cam shafts, valve seats and other parts. When repairing diesel engines, Cummins Inc. uses $3 \mathrm{D}$ technology to restore the cylinder heads. It involves the operations of removing the worn surface of the head by machining, and then by $3 \mathrm{D}$ printing applying a wear-resistant powder coating. The scientifically-based choice of the powder brand for coating allows you to get the wear resistance of the surface of the restored diesel head not only at the level, but sometimes even higher than that of the serial head [5].

\section{Conclusion}

The studies showed the fundamental possibility of using digital production tools such as optical 3D scanning in repair production. The analysis of literature sources showed that compared to contact tools, 3D scanning improves the accuracy and performance of measurements. This method makes it possible to reduce the duration of defects of parts during repair of machines by 6 times, reduce the level of subjectivity of assessing the technical condition of the part and reduce the labor input of the process by $30 \%$. One of the promising directions of introducing $3 \mathrm{D}$ technologies into repair production is the integrated use of additive technologies and 3D scanning. Additive technologies allow applying special coatings to parts such as cylinder liners, piston rings, cam shafts, valve seats and other parts. Such techniques reduce the additive material consumption from 20 to $90 \%$.

\section{References}

1. M. Erokhin, S. Kazantsev, A. Pastukhov, I. Golubev Engineering for Rural Development. 19. Ser. $19^{\text {th }}$ International Scientific Conference Engineering for Rural Development, Proceedings., 147-152, (2020)

2. O.A. Leonov, N.Z. Shkaruba, I.G. Golubev Technologies and equipment for villages, 12, 38-40 (2020)

3. Decree No. 642 of the President of the Russian Federation The Strategy for Scientific and Technological Development of the Russian Federation (2016)

4. V. Goltyapin, I. Golubev E3S Web of Conferences.Key Trends in Transportation Innovation, KTTI 2019, 01013, (2020)

5. I.G. Golubev, V.F. Fedorenko Prospects for the application of additive technologies in the production and technical service of agricultural machinery. (Moscow, Uright Publishing House, 2020).

6. M.A. Petrov, I.S.A. El-Deeb, AIP Conference Proceedings, 2113, 150021 (2019).

7. I.G. Golubev, N.P. Mishurov, V.F. Fedorenko, D.M. Skorokhodov, A.S. Sviridov Digital solutions at the technical service of agricultural machinery (Moscow, Rosinformagrotech, 2020).

8. M. Hawryluk, J. Ziemba Measurement, 128, 204-213, (2018)

9. Z. Gronostajski, M. Hawryluk, M. Kaszuba, J. Ziemba Maintenance and Reliability, 18(2), 194-200, (2016)

10. M. Hawryluk, J. Ziemba, P. Sadowski, Measurement and Control, 50(3), 74-86, (2017)

11. Z. Gronostajski, M. Hawryluk, M. Kaszuba, P. Widomski, J. Ziemba International journal of automotive technology, 18(4), 653-662, (2017)

12. D. Mejia-Parra, J.R. Sánchez, O. Ruiz-Salguero, M. Alonso, A. Izaguirre, E. Gil, J. Palomar, J. Posada Applied Sciences, 9, 1069, (2019)

13. Y. Bokhabrine, R. Seulin, L.F.C. L. Yan Voon, P. Gorria, G. Girardin, M. Gomez, D. Jobard Machine Vision and Applications, 23, 417-425, (2012)

14. T. Koutecky, D. Paloušek, J. Brandejs Measurement, 94, 60-70, (2016)

15. N.M. Yunusbaev Agricultural machines and technologies, 1, 4-8, (2019) 